\title{
THE FIRST SUBTERRANEAN FRESHWATER PLANARIANS FROM NORTH AFRICA, WITH AN ANALYSIS OF ADENODACTYL STRUCTURE IN THE GENUS DENDROCOELUM (PLATYHELMINTHES, TRICLADIDA, DENDROCOELIDAE)
}

\author{
Abdul Halim Harrath ${ }^{1,2 *}$, Ronald Sluys ${ }^{3}$, Adnen Ghlala ${ }^{4}$, and Saleh Alwasel
}

\begin{abstract}
The paper describes the first species of freshwater planarians collected from subterranean localities in northern Africa, represented by three new species of Dendrocoelum Örsted, 1844 from Tunisian springs. Each of the new species possesses a well-developed adenodactyl, resembling similar structures in other species of Dendrocoelum, notably those from southeastern Europe. Comparative studies revealed previously unreported details and variability in the anatomy of these structures, particularly in the composition of the musculature. An account of this variability is provided, and it is argued that the anatomical structure of adenodactyls may provide useful taxonomic information.
\end{abstract}

\section{INTRODUCTION}

The French zoologists C. Alluaud and R. Jeannel were among the first workers to research in some detail the subterranean fauna of Africa (see, Jeannel and Racovitza, 1914). Subsequently, an increasing number of groundwater species were reported from African caves (Messana, 2004). Although the continent has not been extensively explored from a biospeleological perspective, the list of African subterranean-dwelling animals is long (Messana, 2004), but has not included flatworms. The subterranean aquatic fauna of Tunisia has received scant attention, despite the presence of a large number of wells, springs, and caves, notably in the northwestern part of the country. The first study in Tunisia on the subterranean fauna resulted in the first description of a new species of Thermosbaenacea, Thermosbaena mirabilis Monod, 1924 from Africa (Seurat 1921, 1934). During the past decade, only a few explorations of subterranean habitats in Tunisia have been undertaken, resulting in the finding of new records and new species of gastropods and crustaceans (Juberthie et al., 2001; Ghlala et al., 2009). However, subterranean flatworms have not been previously reported from North Africa. In the present paper, we describe three new species of dendrocoelid freshwater flatworms from Tunisia, representing the first planarians to be reported from subterranean localities in North Africa.

The freshwater planarian family Dendrocoelidae basically has a Holarctic distribution, albeit that there are major areas within this biogeographic region from which specimens have not yet been reported (Ball and Reynoldson, 1981, Fig. 7). The Dendrocoelidae are especially diverse in the lakes Ohrid and Baikal and in the area of the Carpathian Mountains. From Lake Baikal, especially, numerous morphologically complex genera and species have been reported (Porfirjeva, 1977). The Holarctic range of the Dendrocoelidae includes the northwestern section of North Africa, based on the records of Dendrocoelum vaillanti De Beauchamp, 1955 from the Grande Kabylie Mountains in Algeria and Acromyadenium moroccanum De Beauchamp, 1931 from Bekrit in the Atlas Mountains of Morocco (Sluys, 2007, and references therein). Both species were collected from epigean habitats, in contrast to the species described in the present paper. In addition to these records of $D$. vaillanti and A. moroccanum, De Beauchamp (1954) mentioned finding two immature, eyeless dendrocoelids in the Grande Atlas Mountains in Morocco and an equally immature, ocellated specimen in Aïn Draham in Tunisia.

All three of the new species described in the present paper possess a particular cone-shaped structure in their copulatory apparatus that is also present in many other dendrocoelids, a musculo-glandular organ or adenodactyl. Our comparative studies on other species of the genus Dendrocoelum Örsted, 1844 revealed previously unreported details and variability in the anatomy of these structures, particularly in the composition of the musculature. In this paper, we provide a first account of these anatomical details and their variability and argue that the anatomical structure of adenodactyls may provide useful taxonomic information.

\footnotetext{
* Corresponding author: halim.harrath@laposte.net

${ }^{1}$ Zoology Department, College of Science, King Saud University, PO Box 2455, Riyadh 11451, Saudi Arabia

${ }^{2}$ Research Unit Animal Reproduction and Developmental Biology, Department of Biology, Faculty of Sciences of Tunis, 2092 Manar II, Tunisia

${ }^{3}$ Institute for Biodiversity and Ecosystem Dynamics \& Netherlands Centre for Biodiversity Naturalis, University of Amsterdam (section ZMA), P. O. Box 94766, 1090 GT Amsterdam, The Netherlands

${ }^{4}$ Unité de Recherche de Biologie Animale et Systématique Evolutive, Faculté des Sciences de Tunis, 2092 Manar II, Tunisia
} 


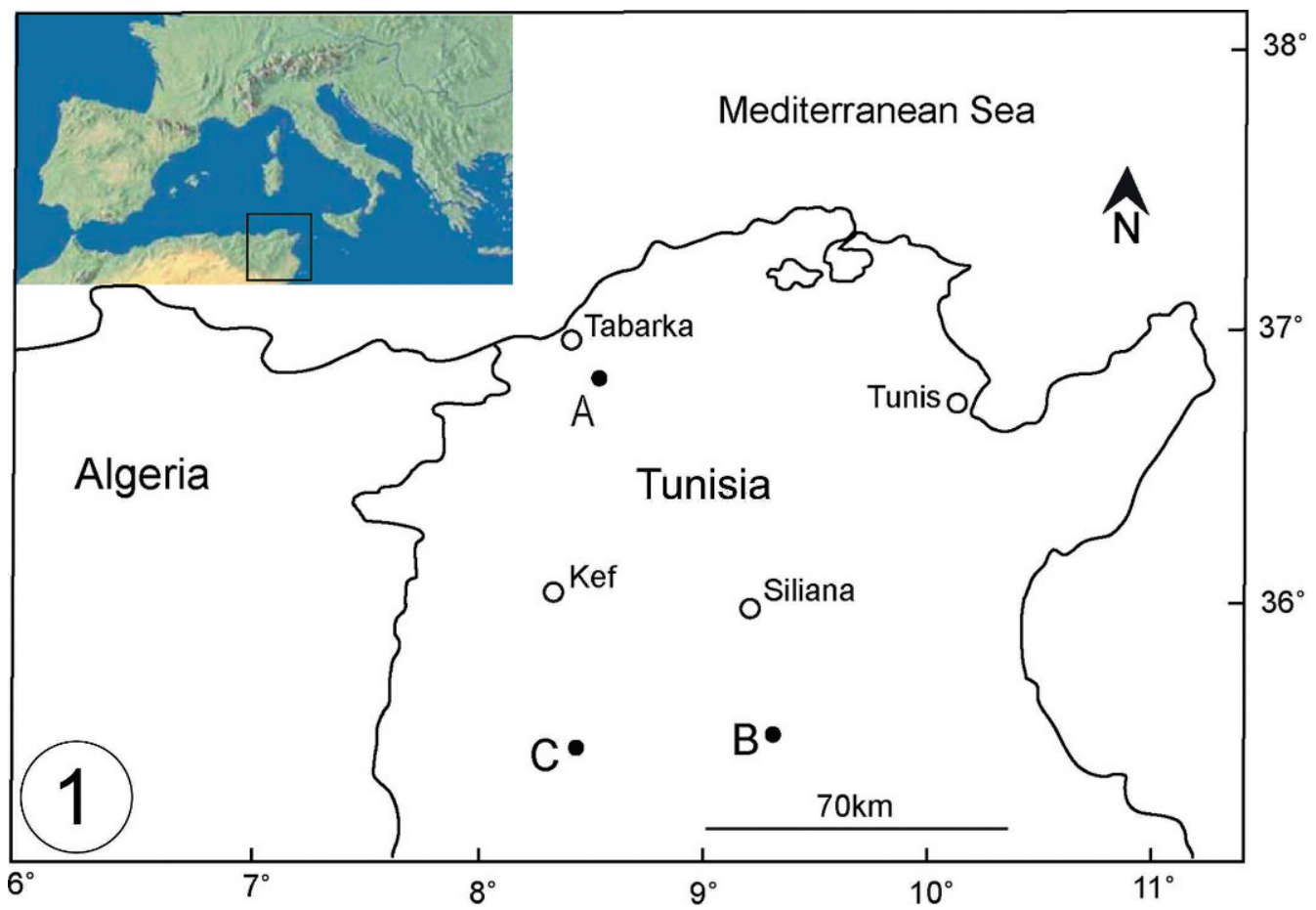

Figure 1. Sampling localities: A, Ain Sobah (Jendouba); B, Ain Dar Forn (Siliana); C, Ain El Ajmi (Kef).

\section{Material AND Methods}

Flatworms were collected from three different natural springs in Tunisia. Each spring feeds an artificial reservoir of about $1 \mathrm{~m}^{3}$ from which water flows through a small channel. When the reservoir is completely closed by an iron door on its top, it is not accessible, and penetration of daylight is obstructed. Subterranean species randomly migrate to the reservoir, where, apparently, they find a favorable environment to live, because the current in the channel keeps surface species away. Specimens were collected by sweeping a net several times through the reservoir. If the iron door was closed, and thus the reservoir was not accessible, the outflow of the channel was blocked for at least 5 minutes with a piece of cloth. After removal of the cloth, the flood pulse was channeled through a net to capture the flatworm specimens. Sampled specimens were transported to the laboratory, where they were photographed, fixed in Steinmann's or Bouin's fluid, and preserved in 70\% alcohol. Histological sections were made at intervals of $7 \mu \mathrm{m}$ and stained in Mallory-Cason. Drawings of the copulatory apparatus were first made with the help of a camera lucida attached to a compound microscope, then digitized, and, subsequently, finalized with Adobe Illustrator CS and Snag It. The material examined is deposited in the Zoological Museum of the University of Amsterdam (ZMA).

\section{Systematic Account}

Order Tricladida Lang, 1884

Family Dendrocoelidae Hallez, 1892
Genus Dendrocoelum Örsted, 1844

Dendrocoelum constrictum Harrath and Sluys, sp. nov.

(Figs. 2, 6, and 7)

Material examined. Holotype: ZMA V.Pl.6884.1, Ain Sobah spring located in the northwest of Tunisia, on the route linking Tabarka to Tunis, approximately $20 \mathrm{~km}$ from the sea, December 2008, coll. H. Harrath \& A. Ghlala, sagittal sections on 10 slides.

Paratypes: V.Pl. 6884.2, ibid., sagittal sections on 14 slides, V.Pl. 6884.3, sagittal sections on eleven slides, V.P1. 6884.4, horizontal sections on 6 slides.

Etymology. The specific epithet is derived from the Latin adjective constrictus and alludes to the constriction or diaphragm through which the seminal vesicle communicates with the penial lumen.

Habitat. Specimens were collected from Ain Sobah spring $\left(36^{\circ} 87^{\prime} 20^{\prime \prime} \mathrm{N}, 8^{\circ} 55^{\prime} 01^{\prime \prime} \mathrm{E}\right)$, situated in a wet zone in northwestern Tunisia. This locality is close to the road from Tunis to Tabarka and located at about $10 \mathrm{~km}$ from the latter (Fig. 1, locality A). The worms were frequently found attached to green algae; associated fauna consisted of isopods and gastropods.

Diagnosis. $D$. constrictum is characterized by an unpigmented body; presence of rather small eyes; a common vas deferens opening into a seminal vesicle, which opens at the tip of a conical papilla projecting into the anterior section 

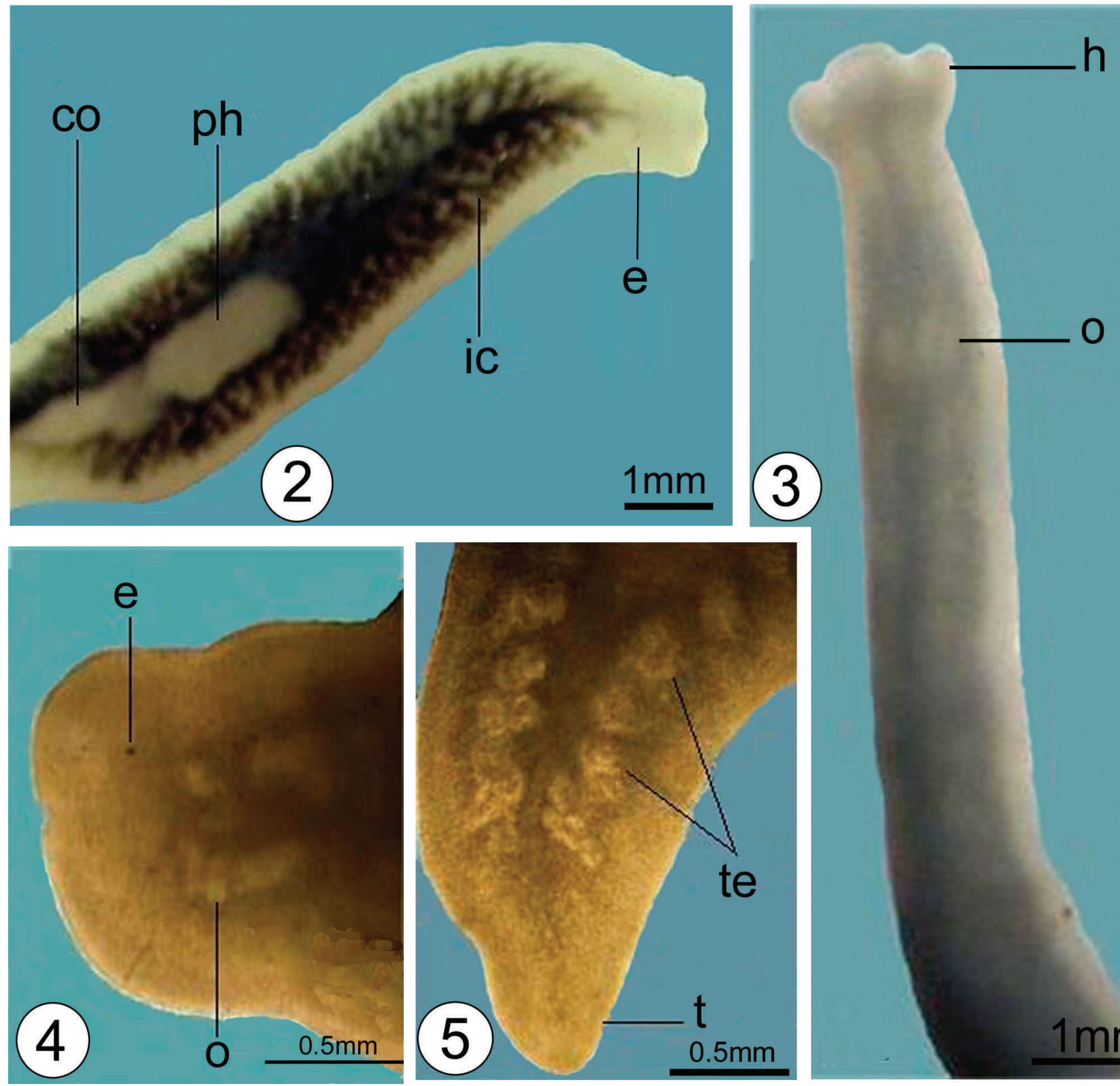

Figures 2-5. 2. Dendrocoelum constrictum, external features of a live specimen. 3. Dendrocoelum duplum, external features of a live specimen. 4. Dendrocoelum amplum, head of a live specimen. 5. D. amplum, posterior end of a live specimen. See caption to Figures 6-11 for key.

of the spacious penial lumen, thus forming a kind of diaphragm; principally dorsal testes, but with also a few ventral follicles; an adenodactyl only slightly smaller than the penis papilla.

Description. Mature specimens in fully stretched state are up to $12 \mathrm{~mm}$ long and $2 \mathrm{~mm}$ wide (Fig. 2). The body is principally unpigmented, but appears beige, red, black or slightly green, depending on the intestinal contents. The rectangular head has rather small eyes that are placed relatively far from the anterior end of the specimen. Although eyes are always present, they are not always 50 - Journal of Cave and Karst Studies, April 2012 clearly visible in live specimens. An adhesive organ was not evident in live or preserved specimens. Histological sections revealed the presence of only a very poorly developed, noncupshaped adhesive organ.

The unpigmented pharynx is positioned entirely in the posterior half of the animal. The muscular system of the internal zone is formed by intermingled circular and longitudinal fibers, which conforms with characteristic pharynx of the family Dendrocoelidae (Sluys and Kawakatsu, 2006, and references therein).

The testes are situated on either side of the body; they are essentially dorsal in position, but with a few, distinctly 
ventral follicles. The testes extend from the level of the ovaries to almost the posterior end of the body. The hemispherical penis bulb consists of intermingled longitudinal and circular muscle fibers (Fig. 6). The more or less conical penis papilla is covered with a moderately thick, nucleated epithelium that is underlain with a layer of circular muscle, followed by a thin layer of longitudinal fibers. The two vasa deferentia run ventrally, but at the level of the copulatory bursa, they curve to the dorsal side and separately enter the penis bulb, after which the ducts unite to form a common vas deferens that opens into a seminal vesicle. The latter opens at the tip of the papilla, which projects into the voluminous proximal section of the penial lumen, thus forming a kind of diaphragm. This wide cavity is lined with a thick, nucleated epithelium.

The adenodactyl (Fig. 7) is slightly smaller than the penis and situated to the right of the latter. It has a spherical and very muscular bulb, with intermingled longitudinal and circular muscle fibers and an elongated papilla. The adenodactyl contains a rather long tubular lumen. Throughout the parenchyma of the papilla extends a layer of fine circular muscle fibers that stains bright blue. Ectally to this zone of circular muscles runs a layer of longitudinal muscle fibers. Entally to the bright blue zone of circular muscles there is also a thin layer of longitudinal fibers.

The ovaries are situated at about one third of the distance between the brain and the root of the pharynx and occupy the entire dorso-ventral diameter of the body. The oviducts arise from the postero-dorsal wall of the ovaries and run ventrally caudad to the level of the copulatory apparatus. They unite to form a common oviduct just behind the copulatory apparatus. This common oviduct receives the secretion of shell glands and opens into the posterior part of the common atrium.

The copulatory bursa is a large sac that occupies almost the entire dorsal-ventral diameter of the body and is situated directly behind the pharynx. The bursa is covered by a thin layer of longitudinal muscles and in mature specimens has a large cavity containing remnants of a spermatophore. The bursal canal arises from the postero-dorsal wall of the bursa and runs latero-dorsally to the male atrium and the penis bulb. It is lined with a thick, nucleated epithelium and is surrounded by two layers of longitudinal muscles. At its distal part, just above the common atrium, the bursal canal widens considerably and is covered with a layer of subepidermal circular muscles, followed by a layer of longitudinal fibers.

Discussion. There are only four other species of Dendrocoelum for which a common vas deferens has been reported: D. puteale Kenk, 1930, D. kenki De Beauchamp, 1937, D. jablanicense (Stanković and Komárek, 1927), and D. botosaneanui Del Papa, 1965. Therefore, we will restrict our comparative discussion to these four species. In contrast to $D$. constrictum, the sperm ducts fuse outside of the penis bulb in D. botosaneanui, D. puteale, and D. kenki (De Beauchamp, 1932, 1937; Del Papa, 1965). It is only in $D$. jablanicense that the sperm ducts first enter the penis bulb and then fuse to form a common vas deferens (Kenk, 1978), as is the case with D. constrictum. However, in $D$. jablanicense the testes are ventral, contrasting with the dorsally placed follicles in $D$. constrictum. In $D$. botosaneanui and $D$. puteale the testes are situated centrally and dorsally in the body, respectively, whereas in $D$. kenki they have a ventral position.

Apart from the point of fusion of the vasa deferentia and the position of the testes, there are a few other details of the copulatory apparatus worth mentioning in which $D$. constrictum either differs from or agrees with the four other species of Dendrocoelum mentioned above. D. constrictum resembles $D$. jablanicense, $D$. kenki, and $D$. puteale in that they all lack a flagellum in the penis papilla, whereas $D$. botosaneanui does have a flagellum. In $D$. constrictum, $D$. jablanicense, and D. kenki the adenodactyl is situated on the right side of the midline of the body, whereas in $D$. puteale it is located on the left side; the precise situation in $D$. botosaneanui is not clear from its description. In both $D$. constrictum and $D$. botosaneanui the adenodactyl is somewhat smaller than the penis, whereas in D. jablanicense and $D$. puteale the adenodactyl is bigger than the male organ; in D. kenki the adenodactyl and the penis are about the same size.

Both $D$. constrictum and D. jablanicense possess eyes, whereas these are absent in $D$. botosaneanui, D. kenki, and D. puteale.

A characteristic feature of $D$. constrictum is that the seminal vesicle opens at the tip of a conical papilla projecting into the proximal, anterior section of the lumen of the penis papilla. A similar projection is also present in D. kenki and D. racovitzai De Beauchamp, 1949, but on the basis of other features $D$. constrictum cannot be equated with either of these two species.

Dendrocoelum duplum Harrath and Sluys, sp. nov.

(Figs. 3, 8, and 9)

Material examined. Holotype: ZMA V.Pl. 6885.1, Ain El Ajmi spring, located in the northwest of Tunisia, at $12 \mathrm{~km}$ from Dahmani village, December 2008, coll. H. Harrath and A. Ghlala, sagittal sections on 12 slides.

Paratypes: V.Pl. 6885.2, ibid., sagittal sections on 8 slides.

Etymology. The specific epithet is derived from the Latin adjective duplus, double, and refers to the presence of two constrictions or diaphragms in the male duct running through the penial papilla.

Habitat. The material examined was collected from Ain El Ajmi spring (Fig. 1, locality C) $\left(35^{\circ} 51^{\prime} 03^{\prime \prime}\right.$ N, $8^{\circ} 47^{\prime} 52^{\prime \prime}$ E).

Journal of Cave and Karst Studies, April 2012 •51 

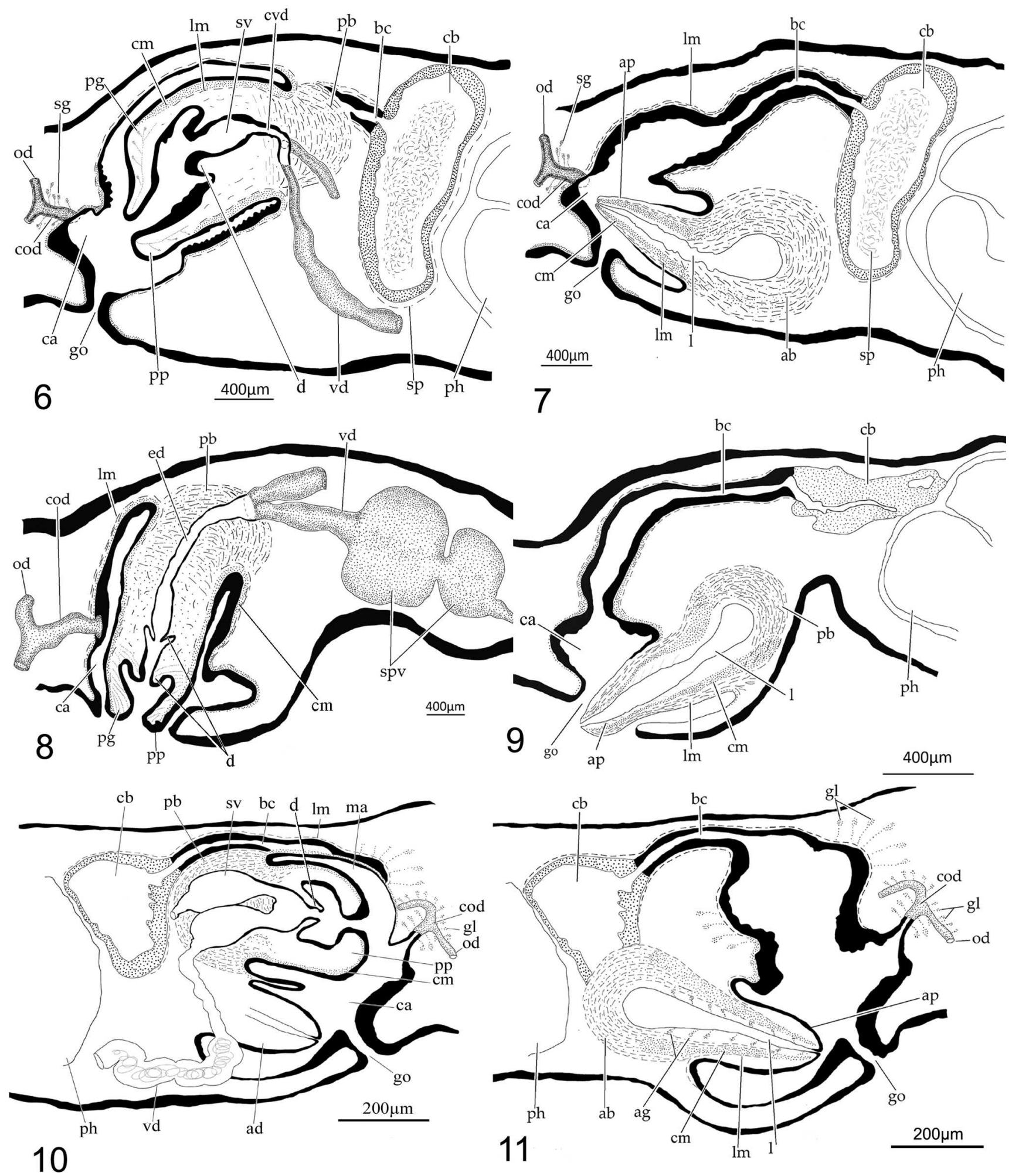

Figures 6-11. 6. Dendrocoelum constrictum. ZMA V.PI. 6884.1, sagittal reconstruction of the copulatory apparatus at the level of the penis (anterior to the right). 7. D. constrictum. ZMA V.PI. 6884.1, sagittal reconstruction of the copulatory apparatus at the level of the adenodactyl (anterior to the right). 8. Dendrocoelum duplum. ZMA V.PI. 6885.1, sagittal reconstruction of the copulatory apparatus at the level of the penis (anterior to the right). 9. D. duplum. ZMA V.PI. 6885.1, sagittal reconstruction of the copulatory apparatus at the level of the adenodactyl (anterior to the right). 10. Dendrocoelum amplum. ZMA V.PI. 6886.1, sagittal reconstruction of the copulatory apparatus at the level of the penis (anterior to the left). 11. D. amplum. ZMA V.PI. 6886.1, sagittal reconstruction of the copulatory apparatus at the level of the adenodactyl (anterior 
This locality is not very far from the Roman ruins of El Medeina and located about $12 \mathrm{~km}$ from the town of Dahmani. Accompanying fauna: a large number of isopods.

Diagnosis. $D$. duplum is characterized by an unpigmented body; the presence of broad auricular lobes; testes that are located dorsally as well as ventrally; an almost vertically oriented penis papilla; a diaphragm in the distal section of the ejaculatory duct; an ejaculatory duct that opens at the tip of a blunt papilla, projecting into the penial lumen, thus forming a kind of second diaphragm; an adenodactyl papilla that is considerably smaller than the penis papilla.

Description. Living animals up to $14 \mathrm{~mm}$ long and $1.4 \mathrm{~mm}$ wide. Dorsal surface white. Head of freely moving animals with a truncated anterior margin and a distinct, broadly rounded auricular lobe on either side; eyes absent (Fig. 3). An adhesive organ was not evident in live or preserved specimens.

Testes are situated dorsally, as well as ventrally, extending throughout the body from directly behind the ovaries to almost the tail end. There are only a few (3 to 4 ) testes in the prepharyngeal part of the body, with the majority of the follicles being located in the postpharyngeal part. The penis is provided with a relatively small hemispherical muscular bulb and an elongated, more or less vertically oriented cylindrical papilla (Fig. 8). The papilla is covered with a flat, nucleated epithelium that is underlain by a layer of circular muscle fibers and a very thin layer of longitudinal muscle fibers. The two vasa deferentia run ventrally, and when they arrive at the level of the copulatory bursa, they widen to form two very large spermiducal vesicles. After having narrowed and penetrated the penis bulb, the sperm ducts immediately unite to form a common intrabulbar vas deferens that extends as the ejaculatory duct (Fig. 8). Through a diaphragm this ejaculatory duct communicates with a distal, narrow section of the penis lumen that opens at the tip of a blunt papilla and projects into the proximal part of the lumen of the penis papilla, forming a kind a second diaphragm. This penis lumen receives the abundant secretion of erythrophilic penis glands.

The adenodactyl (Fig. 9), situated ventrally to the left of the penis, is a little larger than the penis and is provided with a conical papilla and a spherical, well-developed bulb. This adenodactyl is provided with a distinctly light-blue- staining zone of circular muscles that runs through the mesenchyme from the bulb to the tip of the papilla. Ectally to this blue zone of circular muscles runs a layer of redstaining longitudinal muscles. A thin layer of erythrophilic longitudinal muscles is also present entally to the blue zone of fine circular muscle fibers. No glands were observed to discharge into the large lumen of the adenodactyl.

The two ovaries are situated just above the ventral nerve cord about one quarter of the distance between the brain and the root of the pharynx. They are relatively large and can be observed in a living mature specimen as two whitish spots. The two oviducts unite to form a relatively long common oviduct that opens into the common atrium. The copulatory bursa is a small sac, situated dorsally and directly behind the pharyngeal pouch. From the bursa runs the bursal canal, which narrows at its proximal section and is only surrounded by a thin layer of longitudinal muscles. Thereafter the duct widens, and at its vertically, dorsoventrally running section, it is surrounded by a thick, subepithelial layer of circular muscles, followed by a thin layer of longitudinal muscles; this section of the canal opens into the dorsal part of the common atrium.

Discussion. Most species of Dendrocoelum have a more or less developed auricular lobe on either side of the head. But the broad lobes of $D$. duplum have not been described for any other species. Only the auricular lobes of $D$. adenodactylosum (Stanković and Komárek, 1927) approach the condition of $D$. duplum (Kenk, 1978, Fig. 5).

With respect to the communication of the vasa deferentia with the penis, four conditions can be distinguished within the genus Dendrocoelum: (1) In the majority of the species, the vasa deferentia separately penetrate the penis bulb and subsequently open into an intrabulbar seminal vesicle. (2) In a smaller number of species, the sperm ducts open into the somewhat expanded proximal portion of the ejaculatory duct. (3) In a number of species, the vasa deferentia open separately into a much more distal section of the ejaculatory duct. (4) In only five species, the vasa deferentia fuse to form an intra- (condition 4a) or extrabulbar (condition 4b) common vas deferens. For these conditions, see discussion above on $D$. constrictum; the difference between condition (4a) and condition (2) resides in the fact that in the former the proximal section of the ejaculatory duct is hardly or not at all expanded. Conditions (2) and (4a) also hold true for D. duplum.

to the right). Abbreviations used in the figures: ab: adenodactyl bulb; ad: adenodactyl; ap: adenodactyl papilla; bc: bursal canal; ca:common atrium; cb:copulatory bursa; $\mathrm{cm}$ : circular muscles; co: copulatory apparatus; cod: common oviduct; cvd: common vas deferens; d: diaphragm; e: eye; ed: ejaculatory duct; gl: glands; go: gonopore; h: head; ic: intestinal caecum; l: lumen; Im: longitudinal muscles; ma: male atrium; o: ovary; od: oviduct; pb: penis bulb; pg: penis glands; ph: pharynx; pp: penis papilla; sg: shell glands; sp: spermatophore; spv: spermiducal vesicle; sv: seminal vesicle; t: tail; vd: vas deferens; te: testes. 


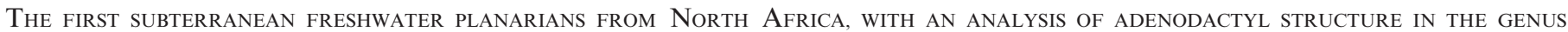
Dendrocoelum (Platyhelminthes, Tricladida, Dendrocoelidae)

Among the species for which conditions (2) or (4a) are applicable, the gross morphology of the copulatory apparatus of $D$. duplum resembles that of $D$. banaticum Codreanu and Balcesco, 1967, D. cavaticum (Fries, 1874), D. chappuisi De Beauchamp, 1932, D. coiffaiti De Beauchamp, 1956, D. maculatum (Stanković and Komárek, 1927), D. polymorphum Codreanu and Balcesco, 1967, D. stenophallus Codreanu and Balcesco, 1967, D. tuzetae Gourbault, 1965, and D. vaillanti De Beauchamp, 1955. However, in all of these species, the vasa deferentia separately traverse the penis a considerable distance before communicating with the ejaculatory duct, whereas in $D$. duplum, the sperm ducts join immediately after they have penetrated the dorsal part of the penis bulb. Furthermore, none of these species show the double valve or diaphragm system of $D$. duplum.

Eyes are absent in $D$. duplum, $D$. banaticum, $D$. chappuisi, D. polymorphum, D. stenophallus, and D. tuzetae, whereas they are present in $D$. cavaticum, $D$. coiffaiti, $D$. maculatum, and D. vaillanti.

\section{Dendrocoelum amplum Harrath and Sluys, sp. nov.}

(Figs. 4, 5, 10, and 11)

Material examined. Holotype: ZMA V.Pl. 6886.1, Ain Dar Forn spring, near Bargou village, located in the governorate of Siliana, December 2008, coll. H. Harrath and A. Ghlala, sagittal sections on 10 slides.

Etymology. The specific epithet is derived from the Latin adjective amplus, spacious, and alludes to the distinct widening of the bursal canal before it opens into the atrium.

Habitat. Animals were collected from Dar Forn spring in the Bargou Mountains (35 58 $52.75^{\prime \prime}$ N, $9^{\circ} 30^{\prime} 43.32^{\prime \prime}$ E), at approximately $1 \mathrm{~km}$ north of the road from Siliana to Ousletia (Fig. 1, locality B). Associated fauna: chiefly isopods.

Diagnosis. $D$. amplum is characterized by a white body; the presence of two small eyes; large testes, situated both dorsally and ventrally; two intrabulbar seminal vesicles, each receiving the openings of a vas deferens; a common intrabulbar seminal vesicle that opens via a diaphragm into the spacious penial cavity; a bursal canal that forms a considerable expansion at the vaginal region; an adenodactyl that is smaller than the penis.

Description. Living specimen up to $8 \mathrm{~mm}$ long and $1.6 \mathrm{~mm}$ wide. Dorsal surface dirty white. Head slightly rounded, with two small eyes situated at equal distance from each other and from the margins of the head (Fig. 4). The anterior end of the animal is provided with an adhesive organ, consisting of a considerable invagination that is lined with an infranucleated epidermis, penetrated by erythrophilic glands.
The numerous, large testes are situated dorsally, as well as ventrally, beginning at the level of the ovaries and extending to almost the tail end (Fig. 5). The subspherical penis bulb is muscular and houses two large seminal vesicles that are situated close to each other and filled with sperm in the holotype specimen (Fig. 10). Each seminal vesicle receives at its anterior section the opening of a sperm duct and, subsequently, opens into a smaller common vesicle. The latter is separated by a large diaphragm from a voluminous penial cavity. This wide cavity is lined with a thick, nucleated epithelium. The papilla is covered with a thick, nucleated epithelium, which is underlain by a layer of circular muscle fibers.

The adenodactyl, located to the left of the penis, is smaller than the latter and is provided with a wide lumen that receives the secretion of glands (Fig. 11). In the muscular hemispherical bulb this lumen expands to form a cavity of regular outline that is surrounded by intermingled layers of longitudinal and circular muscle fibers. The adenodactyl lumen follows a central course through the conical papilla and opens terminally. A layer of fine circular muscle fibers that stains bright blue extends throughout the parenchyma of the papilla. Ectally and entally to this zone of circular muscles runs a layer of longitudinal muscle fibers.

The two spherical ovaries, about $0.22 \mathrm{~mm}$ in diameter, are situated very close to the brain (Fig. 4). The oviducts arise from the postero-ventral side of the ovaries and run ventrally to the level of the copulatory apparatus, where they curve dorsally and unite to form a common oviduct, which opens into the female atrium. The common oviduct, as well as the distal sections of the oviducts, receives the secretion of shell glands. The bursal canal is lined with a thick epithelium and surrounded by a thin layer of longitudinal muscle fibers. The canal runs dorsally to the copulatory apparatus to communicate with a sac-shaped copulatory bursa, situated close to the posterior wall of the pharyngeal pouch and lined with a tall epithelium. The bursal canal expands considerably in diameter at the vaginal area, where it receives the secretion of welldeveloped shell glands and subsequently opens into the female atrium via a slight constriction.

Discussion. Several species of Dendrocoelum are similar to D. amplum in possessing eyes, a vasa deferentia expanded to form large, introbulbar seminal vesicles, or the presence of a distinct widening of the bursal canal. They are similar to the conditions found in $D$. amplum are the following: $D$. adenodactylosum (Stanković and Komárek, 1927), D. maculatum (Stanković and Komárek, 1927), D. jablanicense (Stanković and Komárek, 1927), D. lacustre (Stanković, 1938), D. plesiophthalmum De Beauchamp, 1937.

In both $D$. adenodactylosum and $D$. maculatum the adenodactyl is very large (Kenk, 1978), as compared with the size of the penis, thus contrasting with the condition in D. amplum, in which the adenodactyl and penis are of 
about the same length. $D$. maculatum shares with $D$. amplum the presence of both dorsal and ventral testes, albeit that the follicles are comparatively small in the former and large in the latter.

In $D$. jablanicense, the bursal canal may communicate with the common atrium through one or two openings (Kenk, 1978). However, in this species the vasa deferentia fuse to form a short, intrabulbar common vas deferens, which opens into a seminal vesicle. This situation is strongly different from the course of the vasa deferentia in D. amplum.

Although $D$. lacustre does possess a widened bursal canal near the point of communication with the atrium, it lacks the expanded, intrabulbar seminal vesicles that are characteristic for D. amplum.

Judging from the drawing of the copulatory apparatus published by De Beauchamp (1937, Fig. 3), D. plesiophtalmum does possess the widened section in the posterior part of the bursal canal, but lacks the widened, intrabulbar portions of the vasa deferentia. The long, conical and pointed penis papilla of $D$. plesiophthalmum is rather different from the stubby papilla of $D$. amplum. Unfortunately, the precise morphology and course of the ejaculatory duct through the penis papilla is unknown for $D$. plesiophthalmum.

\section{Anatomy of Adenodactyls in Dendrocoelum}

The presence and precise location of a musculoglandular organ or adenodactyl in the copulatory complex of dendrocoelid planarians has gained some taxonomic importance. For example, the genus Dendrocoelopsis Kenk, 1930 is characterized by the fact, among others, that it lacks an adenodactyl, while several subgenera of Dendrocoelum have been proposed based partly on the shape, size, and location of the adenodactyl (Gourbault, 1972). On the level of species, the size of the adenodactyl in comparison with the penis papilla, and vice versa, forms a useful taxonomic character.

Adenodactyls or comparative structures have been reported for a considerable number of planarians, including land, freshwater, and marine species. Morphological differences suggest that these organs are not homologous and evolved independently in various groups of species (Sluys and Rohde, 1991, and references therein). Adenodactyls occur in several dendrocoelid genera: Dendrocoelum, Caspioplana Zabusova, 1951, Baikalobia Kenk, 1930, Polycladodes Steinmann, 1910, and Acromyadenium De Beauchamp, 1931. Our analysis is restricted to the genus Dendrocoelum, thus likely involving homologous adenodactyls.

Within Dendrocoelum, adenodactyls are cone-shaped structures with a distinct bulb and papilla, provided with a well-developed lumen that receives the abundant secretion of many glands. The precise location, orientation, and shape of the adenodactyl vary between species and form important taxonomic characters that have been taken into consideration by the classical studies on these animals. However, the same studies consistently fail to document the precise arrangement of the musculature of the adenodactyls (e.g., Stanković and Komárek, 1927; De Beauchamp, 1932; Kenk, 1978), thus apparently echoeing Von Graff's (1912-17: 3112) statement that in freshwater planarians all adenodactyls are histologically alike.

However, in the present study and other joint projects, it was noticed that particularly the Dendrocoelum species from the Lake Ohrid region have a histologically characteristic type of adenodactyl. The most striking feature of these adenodactyls is the presence of a zone of fine circular muscle fibers that runs through the mesenchyme of the papilla and stains bright blue when stained with a trichrome stain such as Mallory-Cason. This blue zone runs through the papilla and extends onto the bulb of the adenodactyl. Ectally and entally to this blue zone of circular muscles run layers of longitudinal fibers, which stain red, as do all other muscle fibers in the animal. Especially in Dendrocoelum adenodactylosum this situation can be observed clearly because of the very large size of the adenodactyl (Fig. 12). We observed the same adenodactyl histology in Dendrocoelum maculatum (Stanković and Komárek, 1927) (Fig. 13) and expect the blue zone of fine circular muscles to be present in the adenodactyl of many other species from the Balkan region. We will call this the Balkan type of adenodactyl, albeit that its occurrence is not restricted to this geographic region. For example, it is also present in the widely distributed Dendrocoelum lacteum (Müller, 1774) (Fig. 14). The Balkan type of adenodactyl is also present in the three new Tunisian species described above and in some species from Sardinia (Stocchino et al., in prep.). It is true that in trichrome stains, muscle fibers always stain either blueish or reddish, even in the same preparation. However, the difference with these species of Dendrocoelum is that there is such a clear difference in staining properties of the blue zone of circular muscles of the adenodactyl and the musculature of the rest of the body. For example, in a series of sections of Dendrocoelum amplum from Tunisia that generally show poor affinity for the aniline blue (Wasserblau) component of the MalloryCason stain, the fine circular muscle zone of the adenodactyl, nevertheless, stains bright light blue. The chemical reason why this particular zone of muscles stains so much differently remains an enigma. Reexamination of the material of D. spatiosum Vila-Farré and Sluys, 2011 from northeastern Spain revealed that the thick circular zone of mesenchymal muscles is also present in the adenodactyl of this species, although its differential staining is much less explicit than in the other species mentioned.

The Balkan type of adenodactyl is absent in species such as Dendrocoelum nausicaae Schmidt, 1861 and D. beauchampi Del Papa, 1952. In such species the mesenchymal musculature of the adenodactyl consists predominantly of 


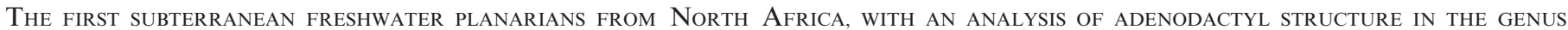
Dendrocoelum (Platyhelminthes, Tricladida, Dendrocoelidae)
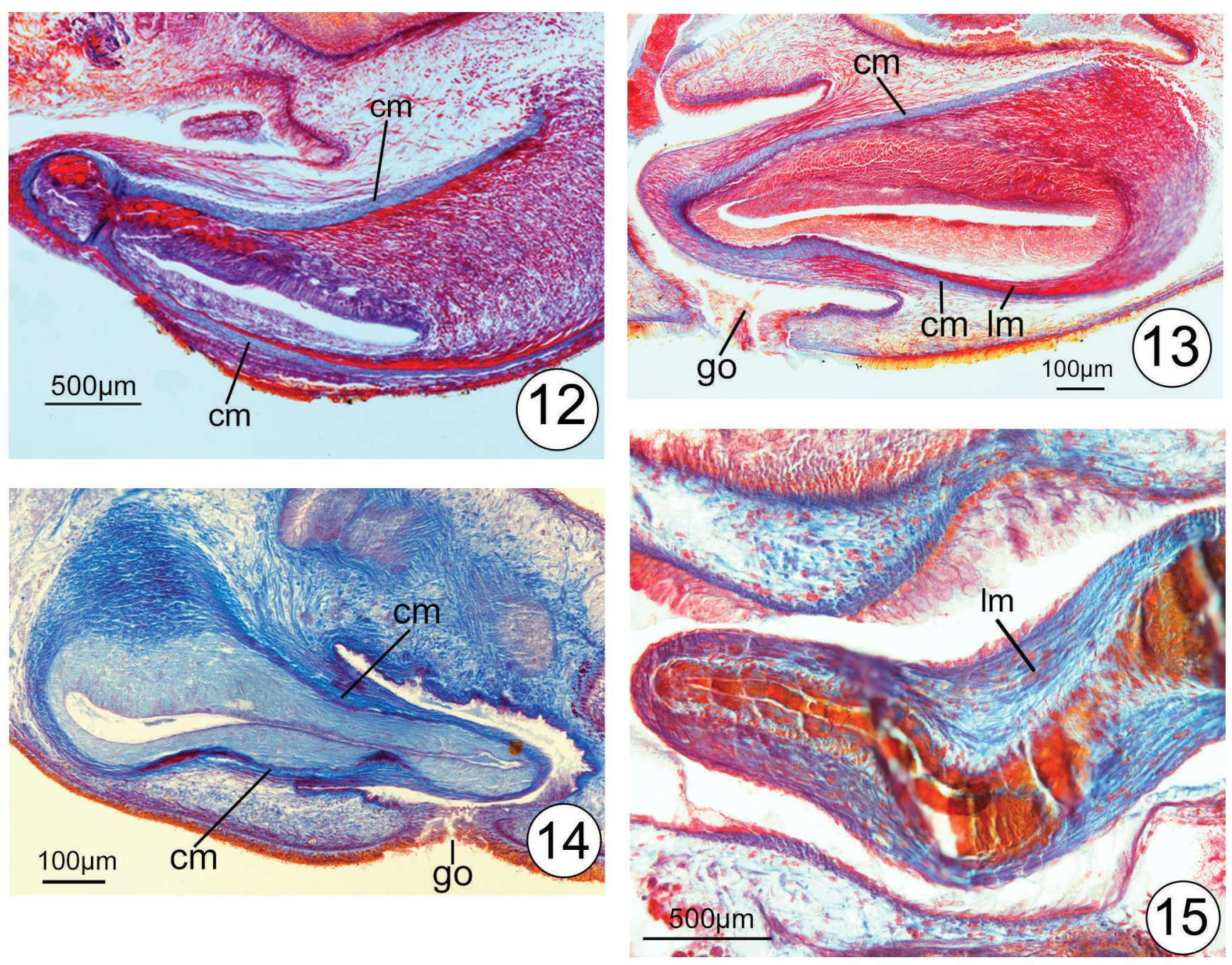

Figures 12-15. 12. Dendrocoelum adenodactylosum from near Resen (Crusje), Macedonia. Photomicrograph of adenodactyl, showing the conspicuous, blue-staining zone of circular muscle. 13. Dendrocoelum maculatum from Bej-Bunar stream near Ohrid, Macedonia. Photomicrograph of adenodactyl, showing the conspicuous, blue-staining zone of circular muscle. 14. Dendrocoelum lacteum from the Ebro delta, Spain. Photomicrograph of adenodactyl, showing the conspicuous, blue-staining zone of circular muscle. 15. Dendrocoelum nausicaae from Corfu, Greece. Photomicrograph of adenodactyl. See caption to Figures 6-11 for key.

longitudinal muscles, with only a thin layer of circular muscles directly underneath the lining epithelium of the lumen of the adenodactyl that stains no differently from the other muscle fibers, as is the case in D. nausicaae (Fig. 15). In $D$. beauchampi, the mesenchymal musculature of the adenodactyl papilla is poorly developed, merely consisting of some circular fibers (Sluys and Benazzi 1992).

Evidently, the precise taxonomic distribution of the Balkan type of adenodactyl needs to be studied and evaluated in more detail in future studies. However, in our opinion present evidence already suggests that presence of this structure signals a closely related group of Dendrocoelum species, which shows a geographically interesting distribution that currently comprises northern Europe, southeastern Europe, Sardinia, northwestern Africa and, most likely, also northeastern Spain.

\section{Acknowledgements}

The authors extend their appreciation to the Deanship of Scientific Research at King Saud University for funding the work through the research group project NoRGP-VPP164.

We are grateful to Miquel Vila-Farré and Giacinta Stocchino for having made available to RS preparations of dendrocoelids from Spain and Sardinia and for sharing with us their information on the anatomy of these animals. Miquel Vila-Farré is also thanked for making available and sectioning specimens of Dendrocoelum lacteum from the Ebro delta in Spain. Prof. Dr. M. Kawakatsu is thanked for nomenclatural advice. A. H. Harrath is indebted to Prof. Fathia Zghal and Prof. Saida Tekaya for their support and encouragement. This work is dedicated to the 
memory of Fattouma, the mother of AHH, without whom he would never have become the person that he is at present. AHH is also grateful for the support of his beloved wife M. Jallouli Harrath, who reinvigorated his taste of life.

\section{REFERENCES}

Ball, I.R., and Reynoldson, T.B., 1981, British Planarians: Cambridge, Cambridge University Press, $141 \mathrm{p}$.

De Beauchamp, P., 1932, Biospeologica LVI, Turbellariés, Hirudinées, Branchiobdellidés, Deuxième Série: Archives de Zoologie Expérimentale et Générale, v. 73, p. 113-380.

De Beauchamp, P., 1937, Turbellariés triclades de Yougoslavie récoltés par MM. Remy et Hubault: Bulletin de la Société Zoologique de France, v. 62, p. 351-365.

De Beauchamp, P., 1954, Nouvelles diagnoses de triclades obscuricoles VIII-IX: Bulletin de la Société Zoologique de France, v. 79, p. $418-427$.

Del Papa, R., 1965, Descrizione di Dendrocoelum (Eudendrocoelum) botosaneanii $\mathrm{n}$. sp. delle grotte del Banato (Romania): Monitore Zoologico Italiano, v. 73, p. 156-162.

Ghlala, A., Della Valle, D., and Messana, G., 2009, First record of the genus Typhlocirolana Racovitza, 1905 (Isopoda: Cirolanidae) from Tunisia and description of a new species from the National Park of Ichkeul: Zootaxa, no. 2176, p. 57-64.

Gourbault, N., 1972, Recherches sur les Triclades paludicoles hypogés: Mémoires du Muséum National d'Histoire Naturelle, nouvelle série (Série A), Zoologie 73, 249 p.

Jeannel, R., and Racovitza, E., 1914, Biospeologica XXXIII: Enumération des grottes visitées 1911-1913: Archives de Zoologie Expérimentale et Générale, v. 53, p. 325-558.

Juberthie, C., Decu, V., Aellen, V., and Strinati, P., 2001, Tunisie, in Juberthie, C., and Decu, V., eds., Encyclopaedia Biospeologica, Tome III: Bucarest, Société Internationale de Biospéologie, p. 1719-1728.

Kenk, R., 1978, The planarians (Turbellaria: Tricladida Paludicola) of Lake Ohrid in Macedonia: Smithsonian Contributions to Zoology, no. 280,56 p.
Messana, G., 2004, Africa Biospeleology, in Gunn, J., ed., Encyclopedia of Caves and Karst Science: New York and London, Fitzroy Dearborn, p. $24-25$.

Porfirjeva, N.A., 1977, Planarii Ozera Baikal: Novosibirsk, Nauka Publishing, 206 p. [in Russian]

Seurat, L.G., 1921, Faune des eaux continentales de la Berbérie: Alger, Publications de la Faculté des Sciences, Travaux du Laboratoire de Zoologie appliquée, $66 \mathrm{p}$.

Seurat, L.G., 1934, Faune aquatique du sud et de l'extrême sud de la Tunisie: Annales des Sciences Naturelles, Zoologie, v. 17, p. 441-450.

Sluys, R., 2007, Annotations on freshwater planarians (Platyhelminthes Tricladida Dugesiidae) from the Afrotropical Region: Tropical Zoology, v. 20, p. 229-257.

Sluys, R., and Benazzi, M., 1992, A new finding of a subterranean dendrocoelid flatworm from Italy (Platyhelminthes, Tricladida, Paludicola): Stygologia, v. 7, p. 213-217.

Sluys, R., and Kawakatsu, M., 2006, Towards a phylogenetic classification of dendrocoelid freshwater planarians (Platyhelminthes): a morphological and eclectic approach: Journal of Zoological Systematics and Evolutionary Research, v. 44, p. 274-284. doi: 10.1111/ j.1439-0469.2006.00371.x.

Sluys, R., and Rohde, K., 1991, A new species of freshwater triclad (Platyhelminthes: Tricladida) from Australia: Zoological Journal of the Linnean Society, v. 102, p. 153-162. doi: 10.1111/j.10963642.1991.tb00286.x.

Stanković, S., and Komárek, J., 1927, Die Süßwasser-Tricladen des Westbalkans und die zoogeographischen Probleme dieser Gegend: Zoologische Jahrbücher Abteilung für Systematik, Ökologie und Geographie der Tiere, v. 53, p. 591-674.

Stocchino, G.A., Sluys, R., Manconi, R., Casale, A., Marcia, P., Grafitti, G., Cadeddu, B., Corso, C., and Pala, M., (in prep.), Triclads from Sardinian groundwaters.

Vila-Farré, M., Sluys, R., Almagro, Í., Handberg-Thorsager, M., and Romero, R., 2011, Freshwater planarians (Platyhelminthes, Tricladida) from the Iberian Peninsula and Greece: diversity and notes on ecology: Zootaxa, no. 2779, p. 1-38.

Von Graff, L., 1912-17, Tricladida, in Dr. H.G. Bronn's Klassen und Ordnungen des Tier-Reichs, Bd. IV Vermes, Abt. IC: Turbellaria, II Abt.: Tricladida: Leipzig, C. F. Winter, p. 2601-3369. 